\title{
On the Discursive Construction of National Image from the Perspective of Appraisal Theory
}

\author{
Zhou Hai-ming ${ }^{1, ~ *, ~ X u ~ Q i a n ~}{ }^{2}$, Jiang Rong-chun ${ }^{1}$, Zhou $\operatorname{Sen}^{1}$ \\ ${ }^{1}$ School of Foreign Languages, Yancheng Teachers University, Yancheng, P. R. China \\ ${ }^{2}$ Center of TEFL, Lvguang Kid Education Co. Ltd, Shanghai, P. R. China
}

Email address:

yczhm@139.com (Zhou Hai-ming)

*Corresponding author

To cite this article:

Zhou Hai-ming, Xu Qian, Jiang Rong-chun, Zhou Sen. On the Discursive Construction of National Image from the Perspective of Appraisal Theory. English Language, Literature \& Culture. Vol. 6, No. 2, 2021, pp. 37-43. doi: 10.11648/j.ellc.20210602.13

Received: June 8, 2021; Accepted: June 21, 2021; Published: June 29, 2021

\begin{abstract}
In the era of globalization, Sino-US relationship is currently the hottest topic, especially in the case of tensions in Sino-US trade relationship, and then the construction of national image of various countries becomes very important. Within the appraisal theory, this paper probes into the construction of national image from three perspectives, namely attitude, engagement and graduation. Through this study, the following findings have been highlighted. First, with reference to appraisal theory, the salient feature is that the text is emphatic. Emphatic words are widely used to enhance momentum of the expression and sharpen attitudes of the two anchors. Second, judgement is mainly used in the ATTITUDE system. Both sides prefer to construct the image of pursuing peaceful coexistence and wishing a better future for each other. Besides, they also incline to seek common ground while preserving difference. Third, heterogloss is the main application of the ENGAGEMENT system in the debate. The application of heterogloss can construct the national image of keeping objective and being fair by invoking a legal provision and using reference data. Fourth, emphatic words account for a high percentage in the debate according to the GRADUATION system. Both sides have a clear and sharp attitude to everything especially in face of the wrong perception of others. And they both construct the image of being gentle and modest, which shows the demeanor of a great country.
\end{abstract}

Keywords: Appraisal, National Image Construction, Discourse of Debate

\section{Introduction}

With the development of globalization, the world has become a big stage and countries all over the world are the actors playing different roles in this special stage. And what is displayed in this big stage can be narrowly regarded as the image of the country, which is similar to the figure of the character in a play. The national image is the outside expression of the country and the exterior show of the spirit core of a country. Therefore, it is important for a country to establish a good national image.

It is generally supposed that debate is that the two sides express conflicting views on the same topic and try to refute the other side's point of view. However, the exact definition of debate is exchange of reasoning and debate is a discussion of subjects. Given such definition, we can regard the dialogue between Trish and Liu Xin as a debate [1]. In addition, such event is an open international communication. As a result, it can have something to do with the construction of national image during the debate.

In the existing studies of national image construction, they tend to research film and television programs and articles and find its influence on the construction of national image. There are a few researches on the debate to discuss about the establishment of the national image. And the appraisal theory provides a feasible theoretical framework to help research the debate discourse and national image construction.

\section{Literature Review}

The research on image construction involves many aspects. Most of the researches are related to journalism and media, drama and television, and politics. Scholars in China have approached national image from various perspectives. Wang Sanhan \& Tan Yaning examined the relationship of media 
transmission and national image construction [2]. They argue that the construction of national image cannot be separated from media transmission. $\mathrm{Li}$ Haiyan investigated the animation culture and national image construction and found its relationship and how to promote the role of animation culture in the construction of national image [3]. Meng Jian revealed the extremely important interactive relationship between the construction of the Chinese government's press release system and the national image [4]. Shang Chongsheng \& Zhao Luyang analyzed the theoretical connotation, dimension and path selection of national image construction which in their point of view is a complex [5].

Recently, some new researches have already appeared. An Yumeng studied the national image construction of the National day celebration report in People's Daily (overseas edition) [6]. She found that the image of China's diverse country was represented through relevant reports. Guan Feng probed into China's national image construction since the founding of the People's Republic, finding that China has constructed images such as socialist powers, oriental powers and global powers, which are getting better on the whole [7].

\section{Theoretical Framework}

The APPRAISAL theory can also be used to evaluate the dialogue texts and research on the national image construction. Through the framework of the APPRAISAL theory, we can carefully study the dialogue wording and the speakers' attitude which can be conveyed by what they said. At the same time, given the nature of the dialogue in the live show, it may have something to do with the construction of national image.

The APPRAISAL theory includes three major sub-systems: ENGAGEMENT, ATTITUDE and GRADUATION. ATTITUDE is sub-systematized into AFFECT, JUDGEMENT and APPRECIATION. ENGAGEMENT is sub-systematized into monogloss and heterogloss. FORCE and FOCUS are included in GRADUATION. In addition, FORCE and FOCUS can be systematized again. All above can be expressed in Figure 1.

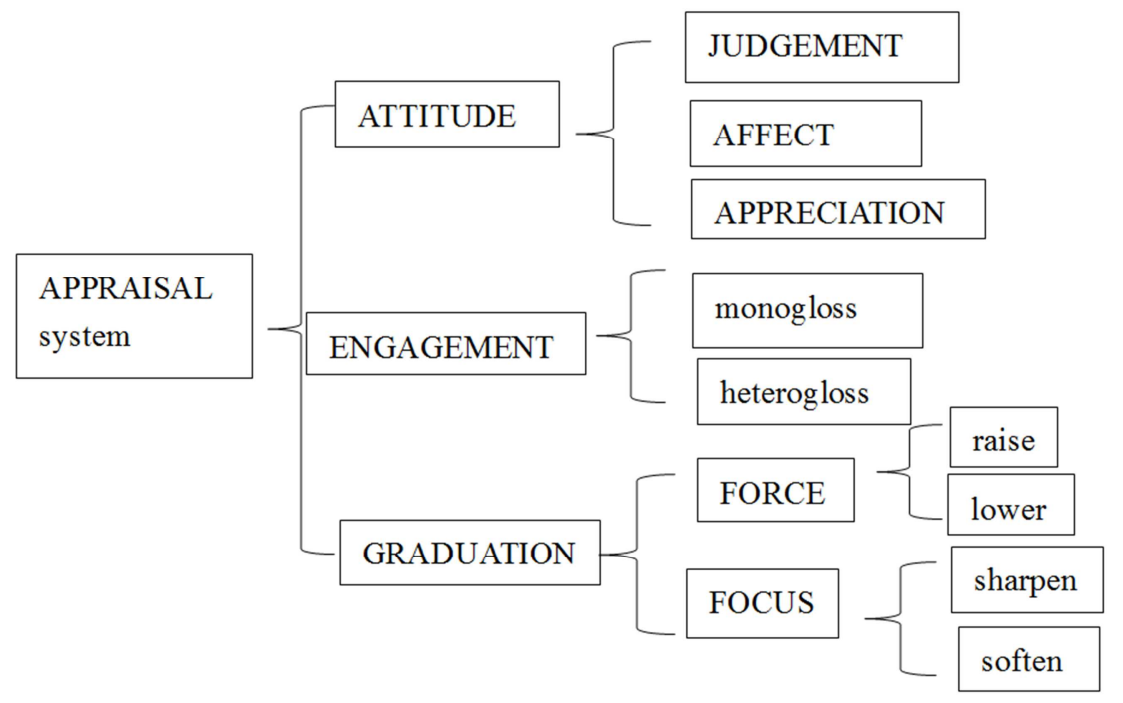

Figure 1. Framework of the appraisal theory (Martin, 2000: 75-142).

ATTITUDE in the APPRAISAL system refers to the stable psychological tendency of an individual to a specific object, such as human behavior, text/ process and phenomena. It includes emotion and judgement. According to Martin, the system is divided into three sub-systems [8].

The first one is the AFFECT system which relates to the emotions of the speakers. In the AFFECT system, feelings can be conveyed by certain words and felt by the reader. Throughout the whole ATTITUDE system, "AFFECT system is the center of the entire ATTITUDE system" [9], and JUDGEMENT system and APPRECIATION system respectively have overlapping parts with AFFECT system.

The second one is the JUDGEMENT system which contains rationality and sensibility. The standards of the JUDGEMENT system are social ethic and social norms. Obviously, on one hand, social ethic which refers to the principles of right and wrong that are accepted by the society is related to the sensibility. On the other hand, the social norms related to judgement are rules and regulations, which goes with rationality. Besides, the system also includes positive and negative appraisal of human behavior. Generally speaking, the JUDGEMENT system is divided into social sanction and social esteem. Social sanction is related to veracity and proprietary while social esteem is relevant to normality, capacity and tenacity.

The third one is the APPRECIATION system which is different from the JUDGEMENT system. In this system, the evaluation of people, things or events is from an aesthetic point of view. Meanwhile, it is associated with the valuation of object. The system is formed around three aspects, namely reaction, composition and valuation. Halliday believes that the reaction is emotional reaction. Therefore, it is in the subsystem of ATTITUDE system [10].

ENGAGEMENT refers to the intervention of attitude in the linguistic sense [11]. Language users use intervention methods to regulate their responsibilities and obligations for what they 
say or write and this is what we called the ENGAGEMENT system. According to Martin's theory, the ENGAGEMENT system can be divided into monogloss and heterogloss.

The last part is the GRADUATION system which is a graded resource for the degree of attitude involvement. It includes two subsystems: FORCE and FOCUS. FORCE is used to the division of the intensity of the energy in language and FOCUS is used to indicate whether the target of the discourse is clear or not. On one hand, FORCE contains the intensity and quantity. On the other hand, FOCUS can be divided into expressions used to sharpen and to soften.

\section{Methodology}

\subsection{Research Questions}

This study was undertaken to approach the following questions:

First, what are the salient features of the dialogue text with reference to evaluation theory of systematic functional linguistic?

Second, from the perspective of vocabulary, what is the way to embody the three subsystems of evaluation theory in the dialogue text?

Third, what are the national images constructed by the debate? And what are the similarities and differences of the national images of the two countries?

Fourth, by means of analyzing vocabulary of the text, what are the opinions or suggestions the study will provide for public speeches, debates, and dialogues in the future?

\subsection{Data in This Study}

The data analyzed in this study is the open debate between anchor Liu Xin of CGTN and anchor Trish Regan of FOX. And the linguistic data is from Full transcript of Liu Xin's live discussion on Fox on the website of CGTN. Fair trade, intellectual property rights, Huawei, tariffs, China's status as a developing country and what the United States calls "state capitalism" were on the agenda. This is the first time that a Chinese anchor and an American anchor have confronted each other, and it is also an opportunity for both sides to hear different opinions. Currently, the Sino-US trade relationship is on a tight rope. Therefore, the reason why this dialogue text is chosen consists in the fact that it is the hottest topic at the moment and it is novel to use the language material of the debate format to study on the construction of national image. Besides, making use of the appraisal theory to research on the international debate is also very newfangled.

\section{Results and Discussion}

When talking about the APPRAISAL theory, we need to pay more attention to the meaning of the word. Conceptually, the evaluation theory is about the expression of discourse or speaker, negotiation, naturalization of the relationship between specific subjects and ideological language resources and the system has its framework.

\subsection{ATTITUDE System}

Firstly, we will talk about the AFFECT system. Human kind is a kind of animals who is the most emotional one and can express their emotion. The value of emotional expression is that it may be the most obvious manifestation of the gesture the speaker takes to a certain phenomenon. Speakers use the language resources to express the emotional impact of events or phenomena on them, and evaluate the phenomenon from the perspective of emotion. Therefore, let's turn to the debate between Trish and Liu Xin. When talking about trade negotiation, Liu Xin and Trish coincidentally used some positive words to express their attitudes to this topic. For example, Liu Xin used "clear" "with respect" "high possibility" and "productive" to convey the standpoint that if the United States show willingness to negotiate, the two countries will achieve good results. They both believed that the United States and China would reach a trade deal. This part expressed their best wishes to the relationship between two countries. It shows the two countries' desire for peaceful coexistence and a better future for each other.

Actually, the two speakers express their emotion by evaluating the event to resonate with audiences in these two countries. According to $\mathrm{Hu}$ Zhuanglin et al, "When the speaker uses emotional expression to evaluate the event, he is actually inviting the audience to share the emotional response with him, or at least he hopes that the audience will regard the emotional response as appropriate, reasonable and understandable." [12] For example, when talking about the intellectual property problem, Trish said: "But I guess we should not really care if it is hundreds of dollars or just 50 cents. How do American business operate in China if they are at risk for having their property, their ideas, their hard work stolen?" Here she used figures of speech, which are exaggeration and rhetorical question, to intensively express her feeling of dissatisfaction. People who were watching the live show might pick up such emotional signals and Americans might have the same feeling. Therefore, when the audience accepted the invitation, the unity or common emotion between the speaker and the audience was strengthened. Once this emotional connection is established, the listener may be open to the broader ideological aspects of the speaker's position. So, the emotional expression helps to keep the audience waiting for the response of Liu Xin. Given that it is an open and live dialogue, the two anchors expressed their opinions and the audiences who shared the idea with them would continue to watch the live broadcast. It is worth mentioning that this part is in the beginning of the conversation. Meanwhile, the discussion aimed at exchanging "different perspectives on this show". Therefore, this way is apparently helpful to the communication between people in the United States and China. This part is good to build the national image of two countries that eagerly hopes to exchange ideas and accepts different opinions.

Between almost every question and answer, judgement can be found after analyzing the dialogue. When talking about intellectual property issues, anchor Trish used the social 
sanction to condemn the behavior that China has stolen enormous amounts of intellectual property which is worth hundreds of billions of dollars. She thought that China had not protect the property of American businesses operate in China yet. In her mind, these enterprises will do business at the risk for having their property, ideas and hard work stolen. Nevertheless, anchor Liu used both social esteem and social sanction in her statement. She believed that many American companies in China are very profitable and the great majority of them would plan to continue to invest in China and explore the Chinese market. Besides, infringement of intellectual property rights is happening all over the world. However, anchor Trish just pointed out some cases in China and equated certain individuals or companies with all Chinese or Chinese companies. It is similar to the way to make a mountain out of a molehill. From this point, it is easy to find that her words can convey the over-generalization thought and can reveal the image of over-amplifying the impact of individual event.

This is just one of the examples in the dialogue. In the conversation, when the topic turned to something happened in China, anchor Trish tended to use the condemn part of social sanction and the critical part of social esteem. For example, Trish mentioned that some American companies perhaps have made some mistakes in terms of being willing to overlook what they might have to give up in the near term, but this is an issue where the country needs to step in. Here she used the word "mistakes" which represents the condemn part of social sanction and judged it according to the property of the behavior. Another example is that she finds the evidence to verify the steal of intellectual property in China. In her statement, she used the verb "steal". This word can convey that she judges the action of China as the critical part of social esteem according to the normality. While talking about the solution and shared vision, she is prone to employ the praise in social sanction and the admiring part of social esteem. For example, when talking about intellectual property, the two anchors both said that you should pay for the acquisition of IP. Obviously, here they agreed with paying for receiving IP, so they appreciated this behavior as the praise in social sanction. Besides, Trish mentioned that to heck with these tariffs, let us get rid of them altogether. This can be treated as the admiring part of social esteem because getting rid of tariffs has the possibility to come true. So, this example is appreciated from the capability in social esteem. In this part, it can show the image of having a clear boundary between right and wrong.

Relatively speaking, throughout the whole conversation, we can find a few examples related to the APPRECIATION system. From my point of view, appreciating something should be objective and fair. Therefore, in the conversation, anchor Trish and anchor Liu used appreciation system to express some objective opinions. For example, to answer the question of the definition of Chinese economic system, anchor Liu responded: "We would like to define it as socialism with Chinese characteristics, where market forces are expected to play the dominating or the deciding role in the allocation of resources. Basically, we want it to be a market economy but there are some Chinese characteristics." Meanwhile, she also said: "So we are, yes, a socialist economy with Chinese characteristics, but not everything is state-controlled, state-run, it's not like that, we are actually quite mixed, very dynamic and actually very very open as well." This part is the appreciation of anchor Liu. She appreciated Chinese economic system and introduced its main characteristics to anchor Trish and all the audiences who were watching the live show. And in this part, Chinese image of tending to have active communication and introduction to other countries can be conducive to show out.

\subsection{ENGAGEMENT System}

In the ENGAGEMENT system, there are monogloss and heterogloss. That is to say, when people take advantage of language to express their attitude, they have two choices. The first one is direct statement. The other one is that they express their opinions and positions indirectly by using others' opinions, thought and position.

The first part is in terms of monogloss. Actually, this is the conversation between Trish and Liu Xin, so it is impossible to elide dialogism. However, at the beginning, anchor Trish use monogloss to introduce anchor Liu. She said that Liu "is the host of a primetime English language television program overseen by the CCP, the Chinese Communist Party". Additionally, Trish said that "as these trade negotiations stall out, it's helpful to know how the Chinese communist party is thinking about trade and about the United States". This is her point of view about the meaning of the open debate. It is worth to say that using monogloss means that the speaker needs to take the responsibility of what he said. Furthermore, she also added that she did not speak for anyone but herself as the host of a Fox Business show. Similarly, Liu Xin also says that she only speaks for herself as a journalist working for CGTN.

Heterogloss means that the speaker may use others' perspective to express the idea. In the whole dialogue, indirect projection, direct projection, extrinsic projection and domain projection can be found to help the two anchors express their opinions. When talking about the economic system and tariff, they use some data to manifest the objectivity of the speech. For example, Liu mentions that $80 \%$ of Chinese employees were employed by private enterprises, $80 \%$ of Chinese exports were done by private companies, $65 \%$ of technological innovation was carried out by private enterprises. Apparently, these statistics are the reflection of domain projection. Employing precise data aims at expressing the idea that not everything in China is state-controlled. It is helpful to make the argument more compelling. Another example is that Trish quoted the trade agreement of 1974, section 301. In the agreement, there is a rule that enables the United States to use tariffs to try and influence the behavior of China if China steals the intellectual property of American. Anchor Trish uses legal provision to express her idea more convincing. She thinks that if China does something illegal, America can use tariffs to protect themselves and confine China. Besides, when talking about forced technology transfer, anchor Liu uses "so-called" which is extrinsic projection to express her own objectivity. "Forced technology transfer" is the word which 
appears at the statement of Trish. Therefore, when Liu Xin uses this word, she repeats it two times to emphasize the word and get the other person's attention. Meanwhile, she uses "so-called" to convey her confusion and needs Trish to give an explanation to the expression.

Beyond that, there are hedging and modality. Hedging refers to vocabulary items with ambiguous meanings. In fact, vague words cannot be found in the conversation. On the other hand, in Wang Zhenhua's view, "modality refers to the range of meaning between affirmation and negation, or intermediate state." [13] In the conversation between two anchors, they both use modal words, such as maybe, perhaps. This is a way of not making things absolute. When using such words, they tend to give the event multiple possibilities because things are rarely black and white. That is to say, they aim to adjust the responsibilities for what they said. Therefore, it is helpful to build the national image of keeping objective and being fair.

\subsection{GRADUATION System}

Apparently, the whole conversation involves five aspects of the graduation system. And the words indicating these aspects are listed in Table 1.

Table 1. Words in the graduation resources.

\begin{tabular}{|c|c|c|c|c|}
\hline \multirow{2}{*}{\multicolumn{2}{|c|}{$\begin{array}{l}\text { FORCE } \\
\text { intensity }\end{array}$}} & \multicolumn{3}{|c|}{ FOCUS } \\
\hline & & \multirow{2}{*}{ quantity } & \multirow{2}{*}{ sharpen } & \multirow{2}{*}{ soften } \\
\hline raise & lower & & & \\
\hline $\begin{array}{l}\text { significant, very, great, never, straight, actually, high, all, majority, } \\
\text { nobody, no country, no individual, every part of, simply, really, certainly, } \\
\text { totally, absolutely, pretty important, much more, effectively, even, so } \\
\text { much cheaper, stronger, exactly, dominating or the deciding role, } \\
\text { important but increasingly smaller, true, the largest, everything, very } \\
\text { very open, greater, better, ultimately }\end{array}$ & $\begin{array}{l}\text { May, would, } \\
\text { possibility, } \\
\text { perhaps, maybe, } \\
\text { probably }\end{array}$ & $\begin{array}{l}1.4 \text { billion, over } \\
\text { three times, less } \\
\text { than one sixth } \\
\text { of, } 9.9 \%, 80 \% \text {, } \\
65 \%\end{array}$ & $\begin{array}{l}\text { Only, just, clear, } \\
\text { that kind of, this } \\
\text { kind of }\end{array}$ & $\begin{array}{l}\text { Enormous amounts } \\
\text { of, hundreds of } \\
\text { billions of, a lot of, a } \\
\text { little bit, a little, } \\
\text { some, years of }\end{array}$ \\
\hline
\end{tabular}

From Table 1, it can be found that among the five parts, intensity occupies the majority. The two anchors use many words which can strengthen the energy in language. It is common that speakers use emphatic words when they are talking about their opinions. If you compare the words of the two anchors, it is apparently that anchor Liu uses more. In the view of the nature of debate, her way of using words which can strengthen the power is reasonable. For example, when answering the question about intellectual property, Liu Xin aims to refute the wrong ideas of Trish and tell the right view to Americans including Trish. Therefore, she says that many American companies in China "are very profitable and the great majority of them" will "plan to continue to invest in China and explore the Chinese market". She is introducing the advantage of doing business in China and then she speaks about the general situation of copyright issues. From her point of view, it is "a common practice probably in every part of the world". Besides, it is wrong that "simply because these cases are happening", you believe that someone is stealing. To sum up, it is unfair to equate a general incident with a certain individual or country. Meanwhile, she also believes that without the protection of IP rights, nobody, no country, no individual can be stronger, can develop itself.

Next example is when they are talking about tariffs. Trish uses two words which can strengthen the power to manifest that she agrees completely with Liu Xin about lowering some of China's tariffs. While, Liu Xin uses more words which are "even", "very complicated", "exactly" and "all". She wants to emphasize that lowering tariffs is a win-win initiative for people in the two countries. At the same time, she also stresses that tariff issue is also a global question and it is necessary to reach a global consensus. This is her way to express self-attitude strongly.

From our point of view, the most typical case is the statement of the definition of economic system in China. Liu
Xin defines the economic system as socialism with Chinese characteristics "where market forces are expected to play the dominating or the deciding role in the allocation of resources". In the definition, she employs two strong words: "dominating" and "deciding" to point out the importance of market force. It helps her to break American's inherent impression to the economic system of China. Additionally, she finally concludes that China has "a socialist economy with Chinese characteristics, but not everything is state-controlled, state-run", and China is "actually quite mixed, very dynamic and actually very very open as well". In her conclusion, she makes use of "everything", "actually", "very" and even "very very" to make a strong impression to all audiences who were watching the live show. And her purpose is to reintroduce economic system to Americans and impress them. Then, we can conclude that this way is helpful to build a strong image of a sharp attitude in the face of the wrong perceptions of others.

Another aspect of intensity is word lowering the energy of the sentence. From the table above, there are a few words representing lower in the conversation. People use lower words to make the whole sentence milder and gentler and to avoid being too strong to give an aggressive feeling. At the beginning, Trish said that she may not agree on everything with Liu Xin. The live show itself is a way for them to communicate with each other and the tone of the beginning need to be soft to welcome the other side. Therefore, anchor Trish showed the acceptance of different points of view from the beginning and showed Liu Xin courtesy. Then, when they talked about tariffs, Liu Xin said that lowering the tariffs would be a wonderful idea. She used "would" to express her own idea and to make her utterance more objective. There is another one example when they talked about the economic system. Liu Xin used "would" and "maybe" to be gentler. She said that she would like to define the economic system as socialism with Chinese characteristics. This is a gentle way to 
introduce a new concept to Americans and it is easy for them to accept it. Then she mentioned that some state-owned enterprises which are playing an important but increasingly smaller role, maybe, in the economy. The modal verb "maybe" is used to express the facts from her perspective. This is the best performance of the national image of being gentle.

When it comes to the quantity part of FORCE, there is a typical case. When Liu Xin reintroduced socialism with Chinese characteristics, she used several data to intensify her attitude fairly. She said that " $80 \%$ of Chinese employees were employed by private enterprises, $80 \%$ of Chinese exports were done by private companies, $65 \%$ of technological innovation was achieved by private enterprises and some of the largest companies that affect our lives, for instance some Internet companies or some $5 \mathrm{G}$ technology companies, are private companies". She used some statistics to prove that not all companies are controlled by the state. These statistics can intuitively express that the majority of companies in China is private enterprise, which is different from the Americans' stereotypes about China and the economic system. And this is good to build the national image of speaking for evidence.

In contrast, words representing FOCUS are relatively few. On one hand, words used to sharpen the focus can give the audience a sense of confidence and then they would understand and accept what you said. When the two anchors greeted with each other, Liu Xin said that she was only speaking for herself. And before this, Trish also conveyed the same meaning. This word can show that what they would say is just a personal position and has nothing to do with the country. Obviously, this show is a platform for civilians in the two countries to exchange their opinions. Therefore, they just don't want to raise the dialogue to the national level. Then, when it comes to intellectual property issues, Liu Xin mentioned that it is a very clear consensus among Chinese society that nobody, no country and no individual can be stronger without the protection of IP rights. She used "clear" to emphasize the consensus plainly and attract the attention of the audience to what she said. Thence, it is helpful to convey the ideas to the audience. In addition, "that kind of" and "this kind of" are also words signifying sharpen. Trish used "that kind of" to refer particularly to the trust between the two countries in valuing intellectual property. She aimed to focus on the trust and wanted the audiences to pay attention to the idea that all need to play by the rules and play by the laws about intellectual property. This aspect is good to construct the national image of having a clear attitude.

On the other hand, there are some words which are used to soften the focus applied in the whole dialogue. These words are used to give the audience a general concept. For example, when talking about the intellectual property issues, Trish mentioned that WTO, as well as DOJ and FBI had announced IP infringement cases. And these cases are the evidence that China has stolen enormous amounts of intellectual property which is worth hundreds of billions of dollars. She employed "enormous amounts of" and "hundreds of billions of" to give the audience a vague impression that China has stolen the intellectual property of American and it is worth a lot of money. This can give the audience who was watching the live show, a sense of shock. And the exaggerated description can impress the audience. Then, Liu Xin responded that U.S. President Donald Trump's tariff makes it a little bit more difficult, makes the future a little uncertain. Liu wanted to blur this part but needed to point out it. Therefore, she used "a little bit" and "a little" to modify the adjectives: difficult and uncertain. Then she can more politely expressed dissatisfaction with the approach of President Trump.

Otherwise, these words are also used in the topic of tariffs. On this topic, Liu Xin stated a fact that the last time the world agrees on the kind of tariff reduction China should commit to, was exactly the result of multilateral and years of difficult negotiations. Here she used "years of" to modify negotiations. It can convey the information that the negotiation of lowering tariffs is very difficult. Because it needs to meet multiple demand and coordinate the opinions of all parties. And this word is to imply a long time to reach a consensus. Then, in the reply of Trish, her statement is that in some ways, it is part of what this all comes back to and it's a sense of trust and some American companies perhaps have made some mistakes in terms of being willing to overlook what they might have to give up in the near term. She made use of "in some ways" and "some mistakes" fuzzy the focal point of the sentence. "In some ways" is used to make her statement more reasonable. She put the essence of the intellectual property issue down to the issue of trust and it can be expressively easier for the audience to accept this kind of statement. Furthermore, "some" is used to fuzzy key word "mistake". She thought that some American companies in China may overlook what they have to give up and this is a wrong decision. This is a euphemistic way to point out that so-called forced technology transfer is under way in China. And then she could express her attitude that she disagreed with what had happened in China.

In addition, the dialogue between Trish Regan and Liu Xin is more a question and answer than a debate. While after analyzing the text in details, we can realize that it is totally a question-and-answer session. Even more, Trish asked more questions and Liu Xin did not have the chance to ask questions. Therefore, Liu Xin tends to answer Trish's questions. The reason leading to such situation is the difference in personality traits and cultural background. American people tend to be more open and enthusiastic. They are also pretty straightforward. However, Chinese people tend to be reserved and gentle. Additionally, people in America advocate freedom and personality. On the contrary, people in China prefer to be courteous. And the difference also resulted in the form of answer and question.

\section{Conclusion}

Through this study, the following major findings have been highlighted.

First, with reference to appraisal theory, the salient feature is that the text is emphatic. In the language text, there are many emphatic words used to enhance momentum of the expression and sharpen attitudes of the two anchors. 
Meanwhile, it is consistent with the attributes of the discourse of debate.

Second, judgement is mainly used in the ATTITUDE system. In this part, the two countries both prefer to construct the image of pursuing peaceful coexistence and wishing a better future for each other. Besides, they are also inclined to seek common ground while preserving difference. For the United States, it represents the image of making a mountain out of a molehill and having clear boundary between right and wrong. Moreover, for China, it is apt to establish the image of having active communication and introduction to other countries.

Third, heterogloss is the main application of the ENGAGEMENT system in the debate. The application of heterogloss can construct the national image of keeping objective and being fair by invoking a legal provision and using reference data.

Fourth, emphatic words are the majority in the debate according to the GRADUATION system. The similarity in the national image is that they both have a clear and sharp attitude to everything especially in face of the wrong perception of others. And they both construct the image of being gentle and modest, which shows the demeanor of a great country.

\section{Funding}

Supported by Jiangsu Province Excellent Social Science Applied Research Project (20SWB-22) and Jiangsu Province Undergraduate Training Program for Innovation and Entrepreneurship (202110324014Z).

\section{References}

[1] CGTN. Full transcript of Liu Xin's live discussion on Fox. [EB/OL] https://news.cgtn.com/news/3d3d774d3245444dd35457a63335 66d54/index.html.
[2] Wang, Sanhan \& Tan, Yaning. On Media Transmission and Construction of National Image. Journal of Shandong Women's University, 2006 (3): 81-84.

[3] Li, Haiyan. Cartoon Culture and National Image Construction. Movie Review, 2006 (22): 15-16.

[4] Meng, Jian. Construction of National Image and China's Institution of News Release. Chinese Journal of Journalism \& Communication, 2008 (11): 33-38.

[5] Shang, Chongsheng \& Zhao, Luyang. National Image Construction: Theoretical Values, Dimensions and Approaches. Journal of Beijing Administration Institute, 2017 (4): 37-43.

[6] An, Yumeng. On the National Image Construction in the $70^{\text {th }}$ National Day Celebration Reports from People's Daily Overseas Edition. Journalism \& Media Studies, 2020 (2): $125-126$.

[7] Guan, Feng. China's Construction of National Image since the Founding of the PRC as a New China. Journal of Beijing Administrative College, 2020 (2): 38-48.

[8] Martin, J. R. Beyond Exchange: Appraisal Systems in English. In S. Hunston \& G. Thompson (eds.). Evaluation in Text: Authorial Stance and the Construction of Discourse. Oxford: Oxford University Press, 2000: 75-142.

[9] Martin, J. R. \& P. White. The Language of Evaluation: Appraisal in English. London: Palgrave, 2005: 44-45.

[10] Halliday, M. A. K. An Introduction to Functional Grammar. London: Edward Arnold, 1994.

[11] Marin, J. R. \& D. Rose. Working with Discourse: Meaning beyond the Clause. London: Continuum, 2003: 58-59.

[12] Hu, Zhuanglin, Zhu, Yongsheng \& Li, Zhanzi. An Introduction to Systemic Functional Linguistics. Beijing: Beijing University Press, 2005: 322.

[13] Wang, Zhenhua. Appraisal Systems and Their Operation: A New Development in the Systemic Functional Linguistics. Journal of Foreign Languages, 2001 (6): 13-20. 